\title{
Hedging Supply Risks: An Optimal Water Portfolio
}

\author{
Anke D Leroux $\quad$ Vance L Martin*
}

\begin{abstract}
Although water supply diversification has been proposed as a solution to dwindling water reserves, the optimal mix of natural and manufactured sources of water remains largely unexplored. We develop a dynamic portfolio model of water supply that hedges against the supply risks from all potential water sources, by taking into account the size of water reserves, uncertainties of water flows as well as differences in supply costs. The optimal portfolio shares for an existing water supply system are derived and compared with the observed contributions to total water stock, revealing unexploited hedging opportunities between various naturally occurring water sources as well as a general over-reliance on manufactured water. The optimal solution implies that future supply augmentations should target natural sources of water ahead of manufactured water. It is estimated that the optimization of the water supply portfolio for a medium-sized city results in annual cost-savings of up to $\$ 463 \mathrm{~m}$.
\end{abstract}

KEYWORDS: manufactured water, optimization, portfolio choice, stormwater, water supply uncertainty

\footnotetext{
*Anke Leroux is a Senior Lecturer at the Department of Economics, Monash University. Vance Martin is a Professor at the Department of Economics, University of Melbourne. The authors thank James Fogarty, John Freebairn, Pedro Gomis-Porqueras, Greg Hertzler, John Quiggin, Paulo Santos and two anonymous reviewers for insightful comments on earlier drafts of this article. Funding from the Victorian Centre for Climate Change Adaptation Research and from the Cooperative Research Centre for Water Sensitive Cities is acknowledged.
} 
Globally, water scarcity is becoming increasingly problematic due to the growing demands of an expanding population and climate change. In many regions, strategic water reserves are being drawn down to dangerously low levels, sparking fears of an impending water crisis. Locally, water supply diversification has been proposed (WWAP, 2012) and adopted as a solution to dwindling reserves as is evident from a recent surge in supply augmenting investments (Rygaard et al., 2011). These investments focus on the development of previously untapped sources of freshwater as well as on technological solutions including wastewater reclamation and the demineralization of sea or inland water sources. However, what constitutes an optimal mix of water supply assets has yet to be determined formally.

We specify a dynamic portfolio model to determine the optimal contributions to total water stock from a broad array of water assets that draw on natural and manufactured sources of water. Large-scale reservoirs and decentralized stormwater harvesting systems, for example, rely on naturally occurring freshwater that is replenished subject to stochastic variations. By contrast, flows of manufactured water using wastewater reclamation or desalination technologies are subject to little or no supply risk. The analytical solution to this model consists of the optimal level of water consumption and the optimal share of each asset in the overall water portfolio. These depend on the size of the water reserve, the source specific water flows, supply risks and costs and the water managers' level of risk aversion.

Calibrating the model to an existing municipal water supply system, our results show that the optimal contributions to total water stock from natural and manufactured sources of water cannot be achieved with the existing portfolio of water supply assets. It is shown that recent augmentation investments under-exploited opportunities to hedge the different risk profiles of the naturally occurring water sources, while relying excessively on manufactured water that is more costly to produce. For our application, the resulting cost savings from optimizing the water supply portfolio range from $\$ 43 m$ to $\$ 463 m$ per year.

Much of the economic literature on water is focused on analyzing the demand side, as reviewed in Arbués et al. (2003), and more recently, by Olmstead et al. (2007) and Nataraj and Hanemann (2011). The price elasticities of residential water demand that are estimated in these studies have important 
implications for managing growing water demand. Similarly, the role and efficiency of water markets in allocating scarce water has been analyzed for example by Michelsen and Young (1993),Weinberg et al. (1993), Easter et al. (1999) and Grafton et al. (2011). However, as evident from the extensive investments that are undertaken to augment the supply capacity of water systems, the economics of water supply seem equally important but have received comparatively less attention in the literature. Some of this literature investigates the economies of scale in the network size of water utilities (Torres and Morrison Paul, 2006; Bottasso and Conti, 2009) and the economics of individual water infrastructure assets, including reservoirs (Oezelkan et al., 1997; Feiring et al., 1998), desalination technology (Fletcher et al., 2007; Salibya et al., 2009) and rainwater tanks (Pickering et al., 2007). Given that these assets tap into different types of water sources, none of which are mutually exclusive, a combination of sources and infrastructure assets may be necessary to reliably generate the desired amount of water, cost efficiently. Mukherjee and Schwabe (2014) estimate a significant and positive effect on agricultural land values from having access to a diversified water supply portfolio that yields greater and more reliable supply. Similarly, the importance of portfolio diversification is recognized in a series of studies concerning the Californian water supply system (see, for example, Tanaka et al. (2006), Hanemann et al. (2006), Medellín-Azuara et al. (2008) and Connell-Buck et al. (2011)) and that of Texas (Kirsch et al., 2009; Kasprzyk et al., 2009). Many of these studies make use of complex, system-specific hydrological optimization models to analyze various supply and demand scenarios. We provide a simpler, theoretical framework with an analytical solution that can be applied to many different water supply settings. With any system augmentations to secure future water supply, important questions arise with respect to the optimal timing of investment. In this context, the use of real option theory has been advocated to determine the optimal timing of investing in new reservoirs (Michailidis and Mattas, 2007) or desalination plants (PC, 2011). This study determines the optimal composition of the urban water supply portfolio, which would precede issues associated with the timing of investment.

The remainder of the paper is organized as follows. In the next section a closed-form solution is derived for the optimal contributions to total water stock from three types of assets, where the flow 
returns from two assets are subject to risk as modelled by correlated but not identical gamma processes, following Wilks (1990) and Groisman et al. (1999). In contrast to financial portfolio models based on Merton (1969) where the optimal shares are constant, the optimal shares in the specified water model are dependent on water stocks, thereby allowing for the important role that strategic reserves play in water systems. The model is applied to Melbourne's existing water supply system, which relies primarily on reservoirs for its water supply, thereby making it comparable to many other water supply systems around the world. Using monthly rainfall and reservoir inflow data from 1915 to 2010 we estimate the moments of the gamma distributions that describe the water supply risk from the conventional and alternative natural water sources. Moreover, the water supply system of Melbourne is of interest because of its recent investment in manufactured water as a means of portfolio diversification (DSE, 2007; MW, 2013). This decision, alongside other readily available data on key parameters, represents an ideal opportunity to infer not only the degree of risk aversion of the implicated decision makers, but also to compare the resulting water portfolio with an optimal portfolio. The empirical estimates from the rainfall and inflow distributions are then used to calibrate the model and to contrast observed and optimal contributions to total water stock and capacity installations for different supply situations. Concluding remarks and general policy implications are provided in the final section.

\section{A Portfolio Model of Water Supply}

A dynamic portfolio model of water is developed that optimizes the supply from three types of water assets, each drawing on a different water source. The analysis is easily extended to include additional or different types of water assets or sources. To match the application in the following sections, the

three water assets are described as follows: the first is a large-scale natural water reservoir, capable of holding important volumes of strategic water reserves (Mukherjee et al., 2010).

The two alternative types of water assets considered draw respectively on harvested stormwater and manufactured water. In the case of manufactured water, water is produced by desalinating sea- 
or brackish water or reclaiming wastewater and its flow is subject to little or no uncertainty. This is not the case for stormwater harvesting, which occurs in small-scale systems that are scattered over predominantly impermeable urban areas. It is worth noting that the stormwater drain discharge in many urban areas is much greater than the runoff that would have naturally occurred and is comparable in quantity to the amount of water supplied to local industry and residents (Mitchell et al., 2007). Stormwater may be collected in traditional drainage, gutter or pipe systems. For example, it has been estimated that a realistic household rainwater tank size within an optimally configured system can cover up to $70 \%$ of annual household demand. Alternatively, stormwater may be harvested within water sensitive urban design features such as ponds, urban wetlands or swales. Treatment of stormwater is usually fit for purpose, which includes open space irrigation, industrial use, car washing, gardens, toilet flushing and washing machines. Stormwater harvesting has been adopted on a large scale in Singapore, where $70 \%$, corresponding to $4000 M L$ per year, of stormwater is harvested and treated for potable use (Lim et al., 1998; DEC, 2006). Similarly, Santa Monica (USA) collects and treats dry weather urban run-off in a reclamation plant with a capacity of $2 M L$ per day (BEC, 1999). In 2012, approximately $242 M L$ were harvested and treated for irrigation purposes as well as for some indoor uses (OSE, 2012).

The differences in system scale, harvesting technique and location yield a different risk profile for harvested stormwater than the profile that describes inflows into large reservoirs. An important feature of the model is the role of uncertainty from inflows and from rain for the total water stock as well as of supply cost heterogeneity when deriving an optimal portfolio of water supply.

\section{Water Stock Dynamics and Consumption}

Let $S_{r}, S_{h}$ and $S_{m}$ be the stocks of reservoir, harvested storm- and manufactured water. The change in these stocks between $t$ and $t+d t$, is specified in terms of the following stochastic differential equation

$$
d S_{i}=\mu_{i} d t+\sigma_{i} d z_{i}, \quad i=\{r, h, m\}
$$


where the parameter $\mu_{i}$ represents the average inflow per annum into each water source, and $d z_{i}$ is a random variable capturing the uncertainty in water flows over time with the strength of the uncertainty determined by the annualized volatility parameter $\sigma_{i}$. The stochastic variables $\left(d z_{i}\right)$ are standardized to have 0 mean and variance $d t$. In the analysis that follows, it is assumed that manufactured water represents a reliable supply source that is not subject to the uncertainty of rainfall and water inflows in general. Formally, this amounts to imposing the restriction $\sigma_{m}=0$ in (1), thereby making manufactured water effectively risk-free in terms of a guaranteed water flow. To allow for interactions amongst water flows of reservoirs and stormwater harvesting within the time interval $d t$, the shocks to water flows are assumed to be dependent, $d z_{r} d z_{h}=\rho d t$, where $\rho=\sigma_{r, h} /\left(\sigma_{r} \sigma_{h}\right)$ is the annualized correlation coefficient and $\sigma_{r, h}$ is the covariance between $d z_{r}$ and $d z_{h}$.

Given the water stocks of reservoirs $\left(S_{r}\right)$, harvested stormwater $\left(S_{h}\right)$, and manufactured water $\left(S_{m}\right)$, the total stock of water for a given portfolio of water supply at time $t, W$, weighted by supply costs, is defined as

$$
W=\sum_{i} \frac{p}{c_{i}} N_{i} S_{i}, \quad i=\{r, h, m\}
$$

where $N_{i}$ is the number of assets of water stock $S_{i}$ held at time $t$, and $p c_{i}^{-1}$ is the ratio of the unit price of water $(p)$ to the total average supply cost from asset $i\left(c_{i}\right)$. This supply cost is defined formally as

$$
c_{i}=\frac{K_{i}}{S_{i}}+\frac{O_{i}\left(S_{i}\right)}{S_{i}}
$$

where $K_{i}$ is the total annualized capital cost for a given source. As the water supply sector is highly capital intensive, capital utilization, as represented by $\frac{K_{i}}{S_{i}}$ in (3), is an important component of the total average cost of supply from asset $i .{ }^{1}$ The term $O_{i}\left(S_{i}\right)$ in equation (3) represents total operating cost, which is a function of the water stock. ${ }^{2}$

Weighting the contribution to total water stock from asset $i$ by its cost of supply in equation (2) recognizes the heterogeneity of water supply technologies and allows for the same amount of water 
supplied from a cheaper source to make a greater contribution to the cost adjusted total water stock than if it were supplied using a more expensive technology.

From (2) the change in the total water stock is given by

$$
\begin{aligned}
d W= & \sum_{i} \frac{p}{c_{i}} d N_{i} S_{i}+\sum_{i} \frac{p}{c_{i}} d N_{i} d S_{i}+\sum_{i} d \frac{p}{c_{i}} d N_{i} S_{i}+\sum_{i} d \frac{p}{c_{i}} d N_{i} d S_{i} \\
& +\sum_{i} \frac{p}{c_{i}} N_{i} d S_{i}+\sum_{i} d \frac{p}{c_{i}} N_{i} d S_{i}+\sum_{i} d \frac{p}{c_{i}} N_{i} S_{i}, \quad i=\{r, h, m\},
\end{aligned}
$$

The first four terms on the right-hand side of this expression represent changes in the water stock that result from changes in the number of assets $\left(d N_{i}\right)$ that draw from a particular water source. The trade-off between capital expansions and current consumption is formalized as

$$
\sum_{i} \frac{p}{c_{i}} d N_{i} S_{i}+\sum_{i} \frac{p}{c_{i}} d N_{i} d S_{i}+\sum_{i} d \frac{p}{c_{i}} d N_{i} S_{i}+\sum_{i} d \frac{p}{c_{i}} d N_{i} d S_{i}=-x(t) d t, \quad i=\{r, h, m\}
$$

where the left-hand side represents investments in new infrastructure and $x(t)$ on the right-hand side is water consumption.

By combining (4) and (5), it follows that

$$
d W=\sum_{i} \frac{p}{c_{i}} N_{i} d S_{i}+\sum_{i} d \frac{p}{c_{i}} N_{i} d S_{i}+\sum_{i} d \frac{p}{c_{i}} N_{i} S_{i}-x d t, \quad i=\{r, h, m\} .
$$

Let the cost-adjusted share of water supply from asset $i$ be defined as

$$
\theta_{i}=\frac{p N_{i} S_{i}}{c_{i} W}, \quad i=\{r, h, m\}
$$

where the sum of $\theta_{i}$ satisfies the normalization restriction

$$
\theta_{r}+\theta_{h}+\theta_{m}=1
$$

Using the equations of water flows for $d S_{i}$ in $(1)$ and $(7)$ in (6) the change in the stock of water is now 
expressed in terms of the shares

$$
\begin{aligned}
d W= & \sum_{i} \mu_{i} \theta_{i} \frac{W}{S_{i}} d t+\sum_{i} \mu_{i} \theta_{i} \lambda_{i} \frac{c_{i}}{p} W d t+\sum_{i} \theta_{i} \lambda_{i} \frac{c_{i}}{p} \sigma_{i}^{2} \frac{W}{S_{i}} d t-x(t) d t \\
& +\sum_{i} \sigma_{i} \theta_{i} \frac{W}{S_{i}} d z_{i}+\sum_{i} \sigma_{i} \theta_{i} \lambda_{i} \frac{c_{i}}{p} W d z_{i}, \quad i=\{r, h, m\}
\end{aligned}
$$

where

$$
\lambda_{i}=\frac{d \frac{p}{c_{i}}}{d S_{i}}=p\left(\frac{K_{i}+O_{i}\left(S_{i}\right)-S_{i}\left(\frac{d O_{i}}{d S_{i}}\right)}{\left(K_{i}+O_{i}\left(S_{i}\right)\right)^{2}}\right) .
$$

As manufactured water in (1) is treated as risk-free, the change in the total weighted water stock is rewritten as

$$
\begin{aligned}
d W= & \left(a_{r} \theta_{r}+a_{h} \theta_{h}+\frac{\mu_{m}}{S_{m}}+\mu_{m} \lambda_{m} \frac{c_{m}}{p}\right) W d t-x(t) d t \\
& +\left(\frac{\sigma_{r}}{S_{r}}+\sigma_{r} \lambda_{r} \frac{c_{r}}{p}\right) \theta_{r} W d z_{r} \\
& +\left(\frac{\sigma_{h}}{S_{h}}+\sigma_{h} \lambda_{h} \frac{c_{h}}{p}\right) \theta_{h} W d z_{h},
\end{aligned}
$$

by using the share normalization restriction in (8), and by defining

$$
\begin{aligned}
& a_{r}=\frac{\mu_{r}}{S_{r}}-\frac{\mu_{m}}{S_{m}}+\mu_{r} \lambda_{r} \frac{c_{r}}{p}+\frac{\sigma_{r}^{2}}{S_{r}} \lambda_{r} \frac{c_{r}}{p}-\mu_{m} \lambda_{m} \frac{c_{m}}{p} \\
& a_{h}=\frac{\mu_{h}}{S_{h}}-\frac{\mu_{m}}{S_{m}}+\mu_{h} \lambda_{h} \frac{c_{h}}{p}+\frac{\sigma_{h}^{2}}{S_{h}} \lambda_{h} \frac{c_{h}}{p}-\mu_{m} \lambda_{m} \frac{c_{m}}{p},
\end{aligned}
$$

which represent respectively the cost-adjusted excess flows from reservoirs and stormwater harvesting, relative to manufactured water.

To complete the specification of total water consumption $(x)$, an iso-elastic utility function with constant average risk aversion and zero transaction costs is assumed

$$
U(x)=\frac{x^{1-\gamma}}{1-\gamma} .
$$

Water utility managers are risk averse for $\gamma>0$, exhibit logarithmic preferences for $\gamma=1$, and relatively high risk aversion for $\gamma>1$. Values of $\gamma<0$, correspond to risk loving preferences. 


\section{Model Solution}

The objective is to choose consumption $(x)$ and the shares of total water stock that are allocated to reservoirs $\left(\theta_{r}\right)$ and stormwater harvesting $\left(\theta_{h}\right)$ to maximize the present value of the utility stream from water consumption for a population growing at the rate $\xi$ and having a discount rate of $\delta$

$$
\max _{x, \theta_{r}, \theta_{h}} E \int_{0}^{\infty}\left(e^{(\xi-\delta) t} \frac{x^{1-\gamma}}{1-\gamma}\right) d t
$$

subject to the water stock flow equation in (10) and the initial condition $W(0)=W_{0}$.

As the utility function in (13) and the water dynamics in (10) are independent of $t$, the optimal solution of (14) is based on solving the dynamic programming problem (see, for example p.248 in Kamien and Schwartz (1981))

$$
\begin{aligned}
(\delta-\xi) V= & \max _{x, \theta_{r}, \theta_{h}}\left(\frac{x^{1-\gamma}}{1-\gamma}+\left[\left(a_{r} \theta_{r}+a_{h} \theta_{h}+\frac{\mu_{m}}{S_{m}}+\mu_{m} \lambda_{m} \frac{c_{m}}{p}\right) W-x\right] V_{W}\right. \\
& +\left[\frac{1}{2}\left(\frac{\sigma_{r}}{S_{r}}+\sigma_{r} \lambda_{r} \frac{c_{r}}{p}\right)^{2} \theta_{r}^{2}+\frac{1}{2}\left(\frac{\sigma_{h}}{S_{h}}+\sigma_{h} \lambda_{h} \frac{c_{h}}{p}\right)^{2} \theta_{h}^{2}\right. \\
& \left.\left.+\left(\frac{1}{S_{r}}+\lambda_{r} \frac{c_{r}}{p}\right)\left(\frac{1}{S_{h}}+\lambda_{h} \frac{c_{h}}{p}\right) \sigma_{r, h} \theta_{r} \theta_{h}\right] W^{2} V_{W W}+O\left(d t^{2}\right)\right),
\end{aligned}
$$

where $V=V(W)$ is the maximum obtainable value expressed in terms of $W$ from the maximization problem in (15), with the first and second derivatives respectively given by $V_{W}$ and $V_{W W}$, and as before $\sigma_{r, h}$ is the covariance between the stochastic processes of reservoirs and harvested stormwater in (1). Maximizing the left-hand side with respect to $x$ and rearranging, expresses the optimal level of water consumption as

$$
x=V_{W}^{-\frac{1}{\gamma}} .
$$

Maximizing the right-hand side of (15) with respect to the shares associated with reservoirs $\left(\theta_{r}\right)$, and 
stormwater harvesting $\left(\theta_{h}\right)$, yields the linear system of equations

$$
\begin{gathered}
a_{r} W V_{W}+\left(\theta_{r}\left(\frac{\sigma_{r}}{S_{r}}+\sigma_{r} \lambda_{r} \frac{c_{r}}{p}\right)^{2}+\left(\frac{1}{S_{r}}+\lambda_{r} \frac{c_{r}}{p}\right)\left(\frac{1}{S_{h}}+\lambda_{h} \frac{c_{h}}{p}\right) \sigma_{r, h} \theta_{h}\right) W^{2} V_{W W}=0 \\
a_{h} W V_{W}+\left(\theta_{h}\left(\frac{\sigma_{h}}{S_{h}}+\sigma_{h} \lambda_{h} \frac{c_{h}}{p}\right)^{2}+\left(\frac{1}{S_{r}}+\lambda_{r} \frac{c_{r}}{p}\right)\left(\frac{1}{S_{h}}+\lambda_{h} \frac{c_{h}}{p}\right) \sigma_{r, h} \theta_{r}\right) W^{2} V_{W W}=0,
\end{gathered}
$$

with solutions

$$
\begin{aligned}
\theta_{r} & =-\left[k_{r} a_{r}-k a_{h}\right] \frac{V_{W}}{W V_{W W}} \\
\theta_{h} & =-\left[k_{h} a_{h}-k a_{r}\right] \frac{V_{W}}{W V_{W W}},
\end{aligned}
$$

where

$$
\begin{aligned}
k_{r} & =\frac{1}{\left(1-\rho^{2}\right)\left(\frac{\sigma_{r}}{S_{r}}+\sigma_{r} \lambda_{r} \frac{c_{r}}{p}\right)^{2}}, \\
k_{h} & =\frac{1}{\left(1-\rho^{2}\right)\left(\frac{\sigma_{h}}{S_{h}}+\sigma_{h} \lambda_{h} \frac{c_{h}}{p}\right)^{2}}, \\
k & =\rho \sqrt{k_{r} k_{h}} .
\end{aligned}
$$

Substituting the optimality expressions (16), (17) and (18) for $x, \theta_{r}$ and $\theta_{h}$ respectively, into the left hand-side of (15), yields the ordinary differential equation

$$
(\delta-\xi) V=\frac{\gamma}{(1-\gamma)}\left[V_{W}\right]^{\frac{\gamma-1}{\gamma}}+\left(\frac{\mu_{m}}{S_{m}}+\mu_{m} \lambda_{m} \frac{c_{m}}{p}\right) W V_{W}
$$

$$
-\frac{1}{2}\left[k_{r} a_{r}^{2}-2 k a_{r} a_{h}+k_{h} a_{h}^{2}\right] \frac{V_{W}^{2}}{V_{W W}}
$$

A closed-form solution for (20) is given by

$$
V(W)=A W^{1-\gamma},
$$


where $A$ is a function of the parameters of the model. To derive $A$, equation (21) is used to rewrite (20) as

$$
((1-\gamma) A)^{\frac{-1}{\gamma}}=\frac{(\delta-\xi)}{\gamma p}-\frac{(1-\gamma)}{2 \gamma^{2} p}\left[k_{r} a_{r}^{2}-2 k a_{r} a_{h}+k_{h} a_{h}^{2}\right]
$$

$$
-\frac{(1-\gamma)}{\gamma p}\left(\frac{\mu_{m}}{S_{m}}+\mu_{m} \lambda_{m} \frac{c_{m}}{p}\right)
$$

Rearranging this expression gives a solution for $A$.

The optimal control function for water consumption is obtained by using (21) and (22) in (16), to give

$$
x=W\left[\frac{(\delta-\xi)}{\gamma}-\frac{(1-\gamma)}{2 \gamma^{2}}\left[k_{r} a_{r}^{2}-2 k a_{r} a_{h}+k_{h} a_{h}^{2}\right]\right.
$$

$$
\left.-\frac{(1-\gamma)}{\gamma}\left(\frac{\mu_{m}}{S_{m}}+\mu_{m} \lambda_{m} \frac{c_{m}}{p}\right)-\frac{(1-\gamma)}{\gamma}\left(\frac{\mu_{m}}{S_{m}}+\mu_{m} \lambda_{m} \frac{c_{m}}{p}\right)\right]
$$

Similarly, using (21) and (22) in (17) and (18) yields

$$
\begin{aligned}
\theta_{r} & =\left[k_{r} a_{r}-k a_{h}\right] \frac{1}{\gamma} \\
\theta_{h} & =\left[k_{h} a_{h}-k a_{r}\right] \frac{1}{\gamma},
\end{aligned}
$$

as the optimal contributions of reservoirs $\left(\theta_{r}\right)$, and stormwater harvesting systems $\left(\theta_{h}\right)$, to total water supply. Using the normalization condition (8) yields the optimal share of manufactured water, $\theta_{m}=$ $1-\theta_{r}-\theta_{h}$

\section{Economic Interpretation}

The optimal level of water consumption given in (23), and the optimal portfolio shares for reservoirs in (24) and harvested stormwater in (25), are all functions of the underlying parameters of the model. 
To highlight some of the salient properties of the model a special case is discussed, whereby the stochastic processes governing reservoir inflows and rainfall are independent $(\rho=0)$ and costs are constant $\left(\lambda_{i}=0\right)$. Upon imposing these conditions, the excess flow equations in (11) and (12) simplify to

$$
a_{r}=\frac{\mu_{r}}{S_{r}}-\frac{\mu_{m}}{S_{m}}, \quad a_{h}=\frac{\mu_{h}}{S_{h}}-\frac{\mu_{m}}{S_{m}}
$$

whilst (19) becomes $k_{r}=S_{r}^{2} / \sigma_{r}^{2}, k_{h}=S_{h}^{2} / \sigma_{h}^{2}$ and $k=0$. Using these results in the expressions for the optimal shares in (24) and (25) yields

$$
\theta_{r}=\left(\frac{\mu_{r}}{S_{r}}-\frac{\mu_{m}}{S_{m}}\right) \frac{S_{r}^{2}}{\gamma \sigma_{r}^{2}}, \quad \theta_{h}=\left(\frac{\mu_{h}}{S_{h}}-\frac{\mu_{m}}{S_{m}}\right) \frac{S_{h}^{2}}{\gamma \sigma_{h}^{2}}
$$

These expressions show that the larger is the average excess flow of water for reservoirs and stormwater harvesting relative to manufactured water, the greater is the optimal contribution to the total water stock from the riskier sources of water

$$
\frac{\partial \theta_{r}}{\partial a_{r}}, \frac{\partial \theta_{h}}{\partial a_{h}}>0
$$

The magnitude of the optimal contributions in (26) are controlled by the size of the risk associated with each water source $\left(\sigma_{i}\right)$. The higher is the risk associated with its supply flow the lower is the water source's optimal share in the water portfolio

$$
\frac{\partial \theta_{r}}{\partial \sigma_{r}}, \frac{\partial \theta_{h}}{\partial \sigma_{h}}<0 .
$$

Moreover, the more risk averse society is with respect to water supply, the smaller are the contributions of the riskier sources of water relative to manufactured water

$$
\frac{\partial \theta_{r}}{\partial \gamma}, \frac{\partial \theta_{h}}{\partial \gamma}<0, \frac{\partial \theta_{m}}{\partial \gamma}>0
$$


In the extreme case of infinite risk aversion

$$
\lim _{\gamma \rightarrow \infty} \theta_{r}, \theta_{h}=0,
$$

the water portfolio is entirely based on manufactured water, $\theta_{m}=1$.

An important feature of the optimal water portfolio in (26) is that individual shares vary over time as they are functions of their respective water stocks

$$
\frac{\partial \theta_{r}}{\partial S_{r}}, \frac{\partial \theta_{h}}{\partial S_{h}}>0
$$

This is in contrast to the optimal solution that arises from the Merton (1969) portfolio model, where the optimal shares are constant. A sufficient condition for the optimal allocations to be time invariant is that $\frac{\mu_{r}}{S_{r}}, \frac{\mu_{h}}{S_{h}}, \frac{\mu_{m}}{S_{m}}, \frac{\sigma_{r}}{S_{r}}, \frac{\sigma_{h}}{S_{h}}$ are constant over time. However, by allowing these ratios to vary over time an important implication of the current model is that it allows for the dynamic contributions of the alternative sources of water to be a function of the prevailing water reserves.

The optimal consumption of water in (23) for the special case of independent stochastic processes $(\rho=0)$ and constant costs $\left(\lambda_{i}=0\right)$, is

$$
x=W\left[\frac{(\delta-\xi)}{\gamma}-\frac{(1-\gamma)}{\gamma}\left(\frac{S_{r}^{2}}{2 \gamma \sigma_{r}^{2}} a_{r}^{2}+\frac{S_{h}^{2}}{2 \gamma \sigma_{h}^{2}} a_{h}^{2}+\frac{\mu_{m}}{S_{m}}\right)\right]
$$

While the rates of discount, $\delta$, and population growth, $\xi$, do not affect optimal shares in (26), they respectively increase and decrease the level of water consumption to be targeted by risk averse water managers, $\frac{\partial x}{\partial \delta}>0$ and $\frac{\partial x}{\partial \xi}<0$ for all $\gamma>0$. Closer examination of this expression reveals that for optimal consumption to be positive, $\gamma$ must exceed a threshold, $\gamma_{\min }$. For example, $\gamma_{\min }=1$ in the case where $\delta=\xi$. Furthermore, optimal consumption decreases in the level of risk aversion

$$
\frac{\partial x}{\partial \gamma}<0
$$


provided that

$$
\gamma>\frac{\frac{S_{r}^{2}}{\sigma_{r}^{2}} a_{r}^{2}+\frac{S_{h}^{2}}{\sigma_{h}^{2}} a_{h}^{2}}{(\delta-\xi)+\frac{S_{r}^{2}}{2 \sigma_{r}^{2}} a_{r}^{2}+\frac{S_{h}^{2}}{2 \sigma_{h}^{2}} a_{h}^{2}-\frac{\mu_{m}}{S_{m}}} .
$$

An important property of the consumption function in equation (27) is that consumption increases linearly with the total stock of water in (2)

$$
\frac{\partial x}{\partial W}>0
$$

This result also is a property of the Merton (1969) portfolio model.

\section{Empirical Inflows and Rainfall Distributions}

The dynamic water flow equations in (1) that arise from either inflows into reservoirs or rainfall, are specified as functions of the mean parameters $\left(\mu_{i}\right)$ and the volatility parameters $\left(\sigma_{i}\right)$. To estimate these parameters a flexible empirical distribution is needed to capture the changing seasonal patterns of reservoir inflows and harvested stormwater over time. Following Wilks (1990) and Groisman et al. (1999) a gamma distribution is specified

$$
g(r ; \alpha, \beta)=\left(\frac{r}{\beta}\right)^{\alpha-1} \exp \left[-\frac{r}{\beta}\right] \frac{1}{\beta \Gamma[\alpha]}, \quad r \geq 0, \quad \alpha, \beta>0,
$$

where $g(r ; \alpha, \beta)$ is the gamma function and $r$ represents either rainfall or inflows. The parameters $\alpha$ and $\beta$ represent the shape and shift parameters of $g(r ; \alpha, \beta)$ respectively. Given the properties of the gamma distribution the means and standard deviations of the flow equations in (1), are related to the gamma parameters respectively as $\mu_{i}=\alpha \beta$ and $\sigma_{i}^{2}=\alpha \beta^{2}$. An advantage of this choice of distribution is that it provides robust estimates of the moments of $g(r ; \alpha, \beta)$ as it takes into account extreme observations.

The parameters of the gamma distribution in (28) are estimated by maximum likelihood methods 
by maximizing the following log-likelihood for a sample of $T$ observations

$$
\begin{aligned}
\ln L & =\frac{1}{T} \sum_{t=1}^{T} \ln g\left(r_{t} ; \alpha, \beta\right) \\
& =(\alpha-1) \frac{1}{T} \sum_{t=1}^{T} \ln \left(\frac{r_{t}}{\beta}\right)-\frac{1}{T} \sum_{t=1}^{T} \frac{r_{t}}{\beta}-\ln \beta-\ln \Gamma[\alpha]
\end{aligned}
$$

As the log-likelihood function in (29) is nonlinear in the parameters $\alpha$ and $\beta$, an iterative gradient algorithm is used to compute the maximum likelihood estimates. All derivatives are computed numerically using MAXLIK in GAUSS Version 10.

To estimate the parameters of the gamma distribution in (29), data on inflows to reservoirs obtained from Melbourne Water, and on rainfall obtained from the Australian Bureau of Meteorology, are used. The data on inflows consist of monthly reservoir inflows beginning January 1915 and ending December 2010, for the four major water reservoirs servicing the city of Melbourne: Maroondah, O'Shannassy, Upper Yarra and Thomson. Aggregating across the four reservoirs for each month yields an aggregate monthly data set of total inflows for reservoirs. A plot of total monthly inflows into all reservoirs is given in figure 1 from 1915 to 2010.

The data on rainfall consist of daily precipitation from 1 January 1915 to 31 December 2010 for six weather stations across Melbourne: Lovely Banks, Meredith, Portarlington, Toorourrong, Yan Yean and Wallaby Creek. These stations are chosen for being High Quality Climate Sites, which are used for climate projections by the Bureau of Meteorology. ${ }^{3}$ The daily data are converted into monthly rainfall by aggregating the daily rainfalls within each month. The monthly rainfall data are then averaged across the six stations for each month. Figure 2 provides a plot of the average rainfall data per month across the six sites from 1915 to 2010 .

Table 1 provides some descriptive statistics on monthly reservoir inflows and rainfall. Inflows and harvested stormwater exhibit large variations over the year. August has the highest inflows into reservoirs with a monthly average of $90244 M L$ over the period 1915 to 2010, while March has the lowest inflows on average of $16356 \mathrm{ML}$. In the case of rainfall it is October that has the highest precipitation 
and January the lowest. The total inflow across all months of the year is $584058 M L$ with a standard deviation of $195424 M L$, and for rainfall the total per annum is $729 \mathrm{~mm}$ with a standard deviation of $147 \mathrm{~mm}$.

The parameter estimates of $\alpha$ and $\beta$ for the gamma distributions for reservoir inflows and rainfall for each month are given in table 2. The estimates of the shape parameter for both distributions for all months are greater then unity, $\widehat{\alpha}>1$, implying a hump-shaped distribution. The scale parameter estimates show some variation over the months to reflect the change in the spread of the distributions from inflows and precipitation over the year. These properties of the water distributions are further highlighted in figures 3 and 4 for inflows and rain respectively, which give the empirical distributions for selected months over the period 1915 to 2010, together with the estimated gamma distributions using the parameter estimates in table 2.

\section{Model Calibration}

The dynamic water portfolio model is calibrated to Melbourne's existing water supply system, which is typical for cities of this size and climate, including, for example, Ahmedabad, Denver and Madrid. Melbourne's water system came under stress during a major drought between 1997 and 2009, which led to the decision in 2007 to diversify the water portfolio by investing $\$ 5.7 b n$ in manufactured water from the desalination of seawater (DSE, 2007, 2009). As consumption and reservoir levels leading up to this decision as well as prior inflows and rainfall are known, this presents an ideal setting to calibrate the model and identify the water managers' level of risk aversion that is implied by this decision.

\section{Choice of Model Parameter Values}

The majority of Melbourne's urban water comes from the four major reservoirs used in the empirical analysis in the previous section, with a total capacity of $1290 G L$ as shown in table 3 . In contrast to these large reservoirs, harvested stormwater is stored in smaller basins that may hold only a fraction of the annual rainfall harvested from the urban catchment area. How much water can be harvested depends on 
local conditions, such as permeability, the size of potential catchment area as well as potential storage constraints and varies widely across stormwater harvesting sites. The parameter values used in this calibration are based on the characteristics of 17 pilot projects across urban Australia. In particular, a mean harvesting rate of $10 \%$ is applied over a catchment area of $355 h a$ with a storage capacity of $0.22 G L$ (CWSC, 2011). ${ }^{4}$ The third asset in the model is calibrated to Melbourne's recently completed desalination plant, which has an annual production capacity of $150 G L$ (MW, 2013). The capital costs per annum associated with the capacities of the three water sources are $K_{r}=\$ 1.2 b n, K_{h}=\$ 0.4 m$ and $K_{m}=\$ 0.66 b n$ for reservoirs, stormwater harvesting and desalination respectively. ${ }^{5}$ The operating costs depend on the amount of treatment required before water can be consumed. While there is some information available on unit operating costs by asset, there is a dearth of information that could be used to inform the functional form and parameterization of $O_{i}\left(S_{i}\right)$ in equation (3). Therefore, the simple case of constant, but heterogenous per unit operating costs by asset is assumed. In parts due to the high energy requirements in desalination, unit operating costs are highest for manufactured water with $\$ 1.08 / k L$ (PC, 2011). Before and after storage treatment or harvested stormwater is required to remove pollutants and to disinfect, costing on average $\$ 0.29 / k L$ (CWSC, 2011). In contrast, reservoir water is harvested from forested catchments that are closed to the public and its treatment requirements are negligible, so that unit operating costs for reservoirs are taken to be $\$ 0.00 / k L$.

The means $\left(\mu_{i}\right)$ and standard deviations $\left(\sigma_{i}\right)$ of the flow equations in (1) are computed using the parameter estimates from the gamma distribution in table 2 . In the case of reservoirs, the parameter estimates of the total annual inflows given in the last row, are used. From the properties of the gamma distribution in (28), the estimates for reservoirs are computed as $\mu_{r}=8.878 \times 65790 \times 10^{-3}=584 G L$, and $\sigma_{r}=\left(8.878 \times 66^{2}\right)^{0.5}=197 G L$. In contrast, the decentralized and small-scale nature of stormwater harvesting systems, which tend to have a faster stock renewal rate than reservoirs, is acknowledged by using the monthly parameter estimates in table 2 to calculate the mean and standard deviation of harvested stormwater across each month of the year. This is done in two steps. First, the monthly estimate of the scale parameter, $\beta$, is annualized by scaling the estimate by 12 . Second, the means 
and standard deviations are then converted into a volume measure by multiplying the rainfall estimate by the catchment area and the harvesting rate. In the case of January for example, the annualized mean is computed as $\mu_{h}=2.185 \times 20.335 \times 12 \times 355 \times 0.1 \times 10^{-5}=0.19 G L$, while the annualized standard deviation is $\sigma_{h}=\left(2.185 \times(20.335 \times 12)^{2}\right)^{0.5} \times 355 \times 0.10 \times 10^{-5}=0.13 G L$. The estimate of the correlation parameter is $\rho=0.475$, which is calculated as the correlation between monthly reservoir inflows and rainfall given in figures 1 and 2 for the total sample period 1915 to 2010 . For desalination, the mean is taken as $\mu_{m}=0$ as the desalination plant has not as yet produced water since being completed. As this source of water is assumed to be riskless, the standard deviation is chosen as $\sigma_{m}=0$

We use a water price $p=2.47 / k L$ which is the wholesale water price in 2013/14 (MW, 2013). The population growth rate for Melbourne is $\xi=0.02(\mathrm{ABS}, 2011)$ and a low discount rate of $\delta=0.03$ is chosen to reflect the long term planning horizon of urban water infrastructure projects.

The relative risk aversion parameter $\gamma$ in the utility function in (13), is calibrated for the year 2007, when the State Government announced the construction of the desalination plant to secure urban water supply (DSE, 2007). This announcement was made at a time when the effects of a Millennium drought from 1997-2009 were at their most severe with reservoirs at merely $30 \%$ capacity. This decision provides the opportunity to infer the level of risk aversion of Melbourne's water policy makers. The relative risk aversion parameter is based on (24), where $k_{r}, k_{h}, k$ are defined in (19) and $a_{r}$ and $a_{h}$ are defined respectively in (11) and (12). At the time of the investment decision, reservoirs operated at $30 \%$ capacity, $S_{r}=0.3 \times 1290 G L=387 G L$. Assuming a comparable capacity utilization for stormwater harvesting systems of $40 \%$, the annual stock of stormwater is $S_{h}=0.4 \times 0.22 M L=0.09 G L$. Hence, the proportion of reservoir water to total water stock is $387 G L /(387 G L+0.09 G L+150 G L)=0.72$. Replacing the left hand-side of (24) with 0.72 and rearranging for $\gamma$ yields an implied risk aversion parameter of $\gamma=3.5 .{ }^{6}$ Put into the context of the constant relative risk aversion parameters that have been estimated in laboratory experiments over monetary outcomes, $\gamma=3.5$ falls into the category of extreme risk aversion, which spans $1.36 \leq \gamma<298$ (Holt and Laury, 2002). An individual with this level 
of risk aversion prefers a lottery that pays $\$ 2.00$ with a probability of $90 \%$ or $\$ 1.60$ with a probability of $10 \%$ to a riskier lottery that pays $\$ 3.85$ with probability $90 \%$ and $\$ 0.10$ with probability of $10 \%$. In light of the essential nature of the commodity 'water' and the serious health and economic consequences of an entire city running out of it, it is not surprising that water managers demonstrate high aversion to water supply risks.

\section{Analysis}

The parameter values described above are now used to compute the optimal portfolio shares for Melbourne. Optimal shares are calculated for three water supply situations. The first case corresponds to the crisis situation in 2007 when water stocks were at an all time low, the second case reflects the long run average water supply and the third case represents a vulnerable supply situation, where water stocks are lower than average but have not reached crisis levels. Figure 5 shows the average costs of supply from reservoirs and stormwater harvesting systems as a function of capacity utilization. The supply costs used in each scenario are calculated based on (3), where the values for $K_{i}$ and $o_{i}$ are reported in table 3. These resulting unit supply costs and underlying stocks are reported in table 4 . It is shown that total unit costs vary between $\$ 1.39 / k L$ and $\$ 3.01 / k L$ of reservoir water and between $\$ 2.69 / k L$ and $\$ 4.79 / k L$ of stormwater depending on the size of water reserves. The lowest costs used correspond to reported total unit costs by Melbourne Water (MW, 2013) and a review of stormwater harvesting pilot sites (CWSC, 2011), which we interpret as reflecting unit cost at long run average capacity utilization. Manufactured water capacity utilization on the other hand is independent of weather variation and can be optimized for each scenario. Hence, we assume total unit supply costs for manufactured water of $\$ 5.45$ for each scenario. This cost corresponds to the long-run average contractual unit price for water sourced from the plant running at full capacity (PWC, 2011).

From (23) optimal consumption $(x)$ is a function of the total stock of water $(W)$, which is weighted by supply costs according to (2). To calculate an optimal physical quantity of consumption that can be compared meaningfully to the various past levels of consumption, we re-weight $W$ by the ratio of the 
supply cost to the price of water. The choice of the supply cost and water price for this re-weighting exercise, is based on the interpretation of consumption in (5), where $x$ is the consumption that must be sacrificed to enable supply augmentation investments in the future. Hence, we re-weight $W$ in (23) by the ratio of the cost of water in the conventional system $\left(c_{r}\right)$ to the price of 'new' water, which we take to be the cost of manufactured water $\left(c_{m}\right)$.

\section{System in Crisis}

Figure 6a shows the optimal shares for the case in 2007 when water reserves in reservoirs were at $30 \%$ and at $40 \%$ across harvesting sites, using a risk aversion parameter of $\gamma=3.5$ and the costs as reported in table 3. The first 12 columns in figure 6 a show how optimal contributions from each source vary across the year, while the second-last column shows the average optimal contribution from each source to total water stock. By construction, the combined share of average optimal contributions from both alternative sources is $28 \%$, which is the share of manufactured water in the observed portfolio (last

column in figure 6a). But our computations show that Melbourne should not have relied entirely on manufactured water. As is shown in column 13, only $14 \%$ of total water supply is manufactured water while harvested stormwater also contributes $14 \%$ to total water supply. The remainder is optimally sourced from reservoirs. It is also shown that optimal contributions from harvested stormwater vary throughout the year with shares being inversely related to rainfall volatility. For example, the highest optimal contribution from stormwater is $26 \%$ in July, which is the month that is characterized by the lowest volatility in rainfall (table 1). These results indicate that there are risk hedging opportunities amongst naturally occurring water sources even during times of crisis.

The physical quantities of water that each source optimally contributes to the total stock are reported in the second column of table 5 and are based on the average optimal share for each source $\left(\theta_{i}\right)$ as shown in figure $6 \mathrm{a}$ and the total water stock $\left(\sum S_{i}\right)$, shown in line 4 of table 5 . Comparing optimal contributions to total crisis stock with observed stocks in column 3 of table 5 shows that reservoir contributions are close to optimal, while an additional $76 G L$ of the total stock should come from 
stormwater harvesting and only $77 G L$ instead of the anticipated $150 G L$ should be manufactured. The optimal level of consumption is calculated based on (23), in which $W$ is weighted by $c_{r} / c_{m}$. The last row of table 5 shows that accounting for crisis water stocks, population growth and the riskiness of the water portfolio yields lower optimal levels of consumption than were observed in 2007/08. Despite water consumption declining from $500 G L$ at the beginning of the drought to $370 G L$ following years of increasingly severe water restrictions, incentivized water saving programs and public education campaigns, annual, the level of consumption exceeds considerably the computed optimal level of $268 G L$. While drought pricing and other dynamic water pricing schemes may lead to further water savings, it is unlikely that these would be sufficient to reduce consumption to the optimal level. In the absence of immediate supply augmentations in proportion of the optimal portfolio, any excess water consumption will have to be met by running down strategic reserves. If these are not being replenished by higher inflows in subsequent years, the optimal supply portfolio will need to be adjusted to the lower reserve level. According to the water portfolio model presented in the first section, this re-adjustment would favour especially manufactured water.

The optimal contributions from table 5 can be extrapolated using the crisis system capacity utilizations of $30 \%$ for reservoirs and $40 \%$ in stormwater harvesting systems to yield the optimal required capacities for each asset. These are reported in table 6 and contrasted with actual installed capacities in the last column. While actual dam capacity is close to optimal for a system in crisis, it is also shown that the optimal annual quantity of harvested stormwater of $190 G L$ far exceeds the currently installed annual capacity of $0.22 G L$. Optimally designed stormwater harvesting technologies are capable of delivering 15 times or more their active storage capacity in annual volume of harvested stormwater (Mitchell et al., 2006). Hence, well integrated stormwater harvesting systems that are purposefully designed to satisfy non-seasonal, constant demand in crisis years may require a physical storage capacity of $13 G L$. This suggests that future supply augmentation investments should be directed towards increasing stormwater harvesting capacity and achieving a greater integration of stormwater harvesting within the demand side of the water sector. Table 6 also shows that the optimal desalination capacity 
is $77 G L$ - about half the capacity of the Wonthaggi desalination plant.

The cost-saving of running an optimal instead of a suboptimal water portfolio in crisis years is reported in the last line of column two in table 7. The total supply costs from the observed portfolio are reported in the first line of table 7 and are calculated by multiplying the observed contributions for each asset (column 3 in table 5) with the relevant supply $\operatorname{costs} c_{r}, c_{h}, c_{m}$, for a system in crisis from table 4 . This yields total annual cost of supply from the observed portfolio of $\$ 1.98 \mathrm{bn}$. The third row in table 7 shows the total annual cost of supply from the optimal portfolio, which is calculated by multiplying the optimal contributions to total stock reported in column two of table 5 with the relevant supply costs and summing across all water sources, $\sum \theta_{i} c_{i} S$. Supplying water in crisis years from a portfolio that is optimized for this situation would cost $\$ 1.94 b n$, resulting in annual cost savings of $\$ 43 m$ per year. ${ }^{7}$ These cost savings arise from having a more diversified portfolio with harvested stormwater being slightly cheaper than desalinated water.

\section{Average System}

Figure $6 \mathrm{~b}$ shows the portfolio shares for the three types of water supply assets that would be optimal under normal conditions, when reservoirs are about $65 \%$ full and stormwater harvesting systems can be expected to hold sufficient water for $75 \%$ of the year. This analysis assumes the same supply cost of desalinated water, $c_{d}=5.45 / k L$, as before. In contrast, lower supply costs from reservoirs, $c_{r}=$ $\$ 1.39 / k L$, and harvested stormwater, $\$ 2.69 / k L$, reflect the greater capacity utilization in these systems on average as compared with crisis years. In particular, the total unit supply costs from reservoirs and stormwater harvesting systems that are reported in annual reports and reviews of stormwater harvesting pilot sites are taken to represent the costs that are observed at long run average capacity utilization. It is shown that, for the same level of risk aversion of $\gamma=3.5$, the optimal share of desalinated water in

the total water stock is $0 \%$. The majority ( $89 \%$ on average) of the water stock in average water years should be supplied by reservoirs. The optimal contribution from stormwater harvesting ranges from $2 \%$ in February, which is characterized by highly volatile rainfall, to $25 \%$ in July. The average share of 
stormwater harvesting across the year is $11 \%$.

The volumetric contributions and implied capacities that arise from this optimal portfolio for average water years are reported in column four of table 5 and column 3 of table 6 . It is shown that current reservoir and stormwater harvesting capacities are insufficient to generate the respectively optimal levels of $877 G L$ and $112 G L$ to the total water stock, while existing desalination capacity is superfluous in average water years. The implication for water sector investments from this result is that supply augmentations that are undertaken to meet the demands of a growing population without reducing the level of strategic reserves, should focus on developing natural sources of water supply, in particular stormwater, instead of targeting manufactured water. As shown in table 5 optimal consumption in long run average years is $434 G L$, or $66 G L$ less than the pre-drought consumption of $500 G L$. This suggests that demand side measures to induce water savings are timely.

The supply costs from the optimal portfolio in long run average years is $\$ 1521 m$, which is $\$ 463 m$ less than the cost of supplying water in an average year to Melbournians given the current portfolio. ${ }^{8}$

\section{Vulnerable System}

Clearly, the desalination plant was built to safeguard Melbourne's water supply not only against crisis situations but perhaps also against lower future average stocks. Figure $6 \mathrm{c}$ shows the optimal shares for a water system that may be considered vulnerable due to lower than average reserve sizes with reservoirs at $45 \%$ capacity and harvested stormwater supplying water with $55 \%$ reliability. It is interesting to note that there is still no case for manufactured water, even for a vulnerable system. ${ }^{9}$ In contrast, the optimal average share of harvested stormwater increases slightly to $14 \%$ as compared with the optimal average share for an average system.

The second-last column in table 5 shows that the optimal contribution of harvested water to total water stock in a vulnerable system is approximately $98 G L$. Table 6 shows that this contribution requires an active capacity of $178 G L$ in harvesting systems of similar efficiency to the piloted systems. Conversely, no desalination capacity is required to deliver the optimal water portfolio in vulnerable 
systems. Optimal consumption in vulnerable systems is $333 G L$ (see table 5). Interestingly, this value is also very close to the actual post-drought consumption of $366 G L$. Inspection of the last column in table 7 shows that sourcing water from the optimal portfolio as opposed to the observed portfolio in vulnerable years yields annual cost savings of $\$ 365 m$.

Therefore, if past water demand and supply policies were driven by the desire to protect Melbourne's water system from greater future vulnerability, our results provide support for the demand side policies but also suggest that supply augmentations should have targeted stormwater harvesting capacity instead of manufactured water.

\section{Concluding Remarks and Policy Implications}

Water supply systems worldwide increasingly struggle to meet the growing demands of an expanding population with conventional sources of supply. In this environment, one may think of a portfolio of water sources that can be developed to augment future water supply. Investment opportunities include previously untapped sources of freshwater, that are often characterized by a different risk profile to conventional surface and groundwater sources. Another alternative to conventional water sources is manufactured water that can be produced at any time and may therefore be considered as completely or almost riskfree. As water supply diversification proceeds fast and at a large scale, we have formally addressed the question of what constitutes an optimal mix of water supply assets.

We specified a continuous-time dynamic model of long-term optimal portfolio allocation across alternative water assets to determine optimal contributions to total water supply from natural and manufactured sources. Water flows from conventional and alternative natural sources are subject to inflow and precipitation volatility, whereas the flow from manufactured water is not weather dependent and thereby considered as riskfree, from a supply source perspective. Important features of the framework consist of the specification for reservoir inflows and rainfall as gamma distributions as well as allowing for heterogeneous and non-linear supply costs. A closed-form solution of the theoretical 
model was shown to exist for optimal consumption and for the optimal individual contributions from the alternative types of water supply assets to total water stock.

The properties of the model were investigated using calibration methods based on parameter values of an existing water supply system that is representative of the supply system of many medium-sized cities around the world. The optimal water consumption and optimal water supply portfolio were computed for different levels of strategic water reserves and compared to the observed level of consumption and the actual water portfolio that resulted from a recent investment in manufactured water.

It was shown that optimal water consumption is only slightly below observed post-drought consumption. This results provides support and further encouragement for current water policies targeting the demand side, which have encouraged water savings through information campaigns and subsidies for water saving devices. Our results also indicate that water consumption during crisis years was considerably higher than optimal crisis-year consumption, despite having achieved significant reductions in water consumption due to the imposition of severe water restrictions. This result suggests that strategic reserves are likely to be drawn down in crisis years. In terms of the recent supply augmentation investments that were undertaken, our results indicate that the pursued investment diversification strategy had under-exploited the risk hedging opportunities between naturally occurring sources of water. It was found that stormwater harvesting should optimally contribute a relative constant share of between $11 \%$ and $14 \%$ of total water stock depending on the level of strategic reserves. Conversely, the recent investment in manufactured water appears to have been excessive. Our results indicate that a desalination plant with half its current capacity would have been optimal for a system in crisis, while no contributions from manufactured water are required for average and vulnerable systems. It was estimated that optimizing the water supply portfolio can yield cost savings of between $\$ 43 m$ to $\$ 463 m$ per year depending on the size of the water reserve.

The overall policy implications from these results are not that the optimal asset composition of the portfolio should change from year to year depending on the size of the strategic water reserve. Instead, we show that the water supply portfolio that should be targeted with future supply augmentation 
investments depends on the circumstance in which the investment is made. For the case considered, water supply augmentations that occur in anticipation of growing future demand and with a view of keeping the size of the reserve constant, should target different natural sources of water and exploit risk hedging opportunities amongst these. In contrast, water infrastructure investments that occur because the size of the strategic reserve has fallen drastically and is unlikely to recover, may target a mix of alternative natural as well as manufactured water sources. 


\section{References}

ABS (2011). Regional population growth, Australia, 2009-10. Technical Report 3218.0, Australian Bureau of Statistics.

Arbués, F., M. Á. Garcıa-Valiñas, and R. Martınez-Espiñeira (2003). Estimation of residential water demand: a state-of-the-art review. The Journal of Socio-Economics 32(1), 81-102.

BEC (1999). Engineering report for dry-weather runoff, reclamation, storage, pumping, distribution, and nonpotable water use area facilities. Technical report, Boyle Engineering Corporation, City of Santa Monica.

Bottasso, A. and M. Conti (2009). Scale economies, technology and technical change in the water industry: Evidence from the english water only sector. Regional Science and Urban Economics 39(2), $138-147$.

Connell-Buck, C. R., J. Medellín-Azuara, J. R. Lund, and K. Madani (2011). Adapting California's water system to warm vs. dry climates. Climatic Change 109(1), 133-149.

CWSC (2011). Sustainable Technologies: Literature and Practice Review. Melbourne: Centre for Water Sensitive Cities.

DEC (2006). Managing urban stormwater: harvesting and reuse.

DSE (2007). Our Water our Future: The Next Stage of the Government's Water Plan. Department of Sustainability and Environment, Victorian Government.

DSE (2009). Project Summary: Victorian Desalination Project. Partnerships Victoria, Department of Sustainability and Environment, Victorian Government.

DTPLI (2009). Victorian Desalination Project Assessment. Department of Transport, Planning and Local Infrastructure. 
Easter, K. W., M. W. Rosegrant, and A. Dinar (1999). Formal and informal markets for water: Institutions, performance, and constraints. The World Bank Research Observer 14(1), 99-116.

Feiring, B. R., T. Sastri, and L. S. M. Sim (1998). A stochastic programming model for water resource planning. Mathematical Computer Modelling 27(3), 1-7.

Fletcher, H., T. Mackley, and S. Judd (2007). The cost of a package plant membrane bioreactor. Water Research 41(12), 2627-2635.

Grafton, R. Q., G. Libecap, S. McGlennon, C. Landry, and B. Oï£Brien (2011). An integrated assessment of water markets: A cross-country comparison. Review of Environmental Economics and Policy 5(2), 219-239.

Groisman, P. Y., T. R. Karl, D. R. Easterling, R. W. Knight, P. F. Jamason, K. J. Hennessy, R. Suppiah, C. M. Page, J. Wibig, K. Fortuniak, V. N. Razuvaev, A. Douglas, E. Førland, and P.-M. Zhai (1999). Changes in the probability of heavy precipitation: Important indicators of climatic change. Climatic Change 42(1), 243-283.

Hanemann, M., L. Dale, S. Vicuña, D. Bickett, and C. Dyckman (2006). The economic cost of climate change inpact on California Water: A Scenario Analysis. California Energy Commission, PIER Energy-Related Environmental Research. CEC-500-2006-003.

Holt, C. A. and S. K. Laury (2002). Risk aversion and incentive effects. American Economic Review 92(5), 1644-1655.

Kamien, M. I. and N. L. Schwartz (1981). Dynamic Optimization: The Calculus of Variations and Optimal Control in Economics and Management, Volume 4 of Dynamic Economics: Theory and Applications. New York: North Holland.

Kasprzyk, J. R., P. M. Reed, B. R. Kirsch, and G. W. Characklis (2009). Managing population and drought risks using many-objective water portfolio planning under uncertainty. Water Resources Research 45, W12401. 
Kirsch, B. R., G. W. Characklis, K. E. M. Dillard, and C. T. Kelley (2009). More efficient optimization of long-term water supply portfolios. Water Resources Research 45, W03414.

Lim, C., N. Lim, and . (1998). Urban stormwater collection for potable use. In A. W. Association and Wastewater (Eds.), 11th IWSA-ASPAC Regional Conference, pp. pp. 571-577.

Medellín-Azuara, J., J. J. Harou, M. A. Olivares, K. Madani, J. R. Lund, R. E. Howitt, S. K. Tanaka, M. W. Jenkins, and T. Zhu (2008). Adaptability and adaptations of californiaï£js water supply system to dry climate warming. Climatic Change 87(1), 75-90.

Merton, R. C. (1969). Lifetime portfolio selection under uncertainty: the continuous-time case. Review of Economics and Statistics 51(3), 247.

Michailidis, A. and K. Mattas (2007). Using real options theory to irrigation dam investment analysis: an application of binomial option pricing model. Water Resources Management 21 (10), 1717-1733.

Michelsen, A. M. and R. A. Young (1993). Optioning agricultural water rights for urban water supplies during drought. American Journal of Agricultural Economics 75(4), 1010-1020.

Mitchell, V., A. Deletic, T. Fletcher, B. Hatt, and D. McCarthy (2007). Achieving multiple benefits from stormwater harvesting. Water Science and Technology 55(4), 135-144.

Mitchell, V. G., B. E. Hatt, A. Deletic, T. D. Fletcher, D. T. McCarthy, and M. Magyar (2006). Integrated stormwater treatment and harvesting: Technical guidance report. Technical report, Institute for Sustainable Water Resources.

Mukherjee, M. and K. Schwabe (2014). Irrigated agricultural adaptation to water and climate variability: The economic value of a water portfolio. American Journal of Agricultural Economics.

Mukherjee, S., Z. Shah, and M. Kumar (2010). Sustaining urban water supplies in India: Increasing role of large reservoirs. Water Resources Management 24(10), 2035-2055.

MW (2013). 2013 Water Plan. Melbourne: State Government of Victoria, Melbourne Water. 
Nataraj, S. and W. M. Hanemann (2011). Does marginal price matter? A regression discontinuity approach to estimating water demand. Journal of Environmental Economics and Management 61(2), $198-212$.

Oezelkan, E. C., A. Galambosi, E. Fernandez-Gaucherand, and L. Duckstein (1997). Linear quadratic dynamic programming for water reservoir management. Applied Mathematical Modelling 21, 591-598.

Olmstead, S. M., M. W. Hanemann, and R. N. Stavins (2007). Water demand under alternative price structures. Journal of Environmental Economics and Management 54(2), 181-198.

OSE (2012). Sustainable santa monica. Technical report, Santa Monica Government, Office of Sustainability and the Environment.

PC (2011). Australia's Urban Water Sector. Final Inquiry Report No. 55. Canberra: The Productivity Commission.

Pickering, P., J. Mikkelsen, and J. Marsden (2007). The Cost-effectiveness of Rainwater Tanks in Urban Australia. Canberra ACT, Australia: National Water Commission, Australian Government.

PWC (2011). Advice to Victorian Government on Cost of Water from the Desalination Plant Under Contract with AquaSure. Melbourne: PricewaterhouseCoopers.

Rygaard, M., P. J. Binning, and H.-J. Albrechtsen (2011). Increasing urban water self-sufficiency: New era, new challenges. Journal of Environmental Management 92, 185-194.

Salibya, I. E., Y. Okoura, H. Shona, J. Kandasamya, and I. S. Kimb (2009). Desalination plants in Australia, review and facts. Desalination 249, 1-14.

Tanaka, S., T. Zhu, J. Lund, R. Howitt, M. Jenkins, M. Pulido, M. Tauber, R. Ritzema, and I. Ferreira (2006). Climate warming and water management adaptation for california. Climatic Change 76(3-4), $361-387$. 
Torres, M. and C. J. Morrison Paul (2006). Driving forces for consolidation or fragmentation of the US water utility industry: A cost function approach with endogenous output. Journal of Urban Economics 59(1), 104-120.

Weinberg, M., C. L. Kling, and J. E. Wilen (1993). Water markets and water quality. American Journal of Agricultural Economics 75(2), 278-291.

Wilks, D. S. (1990). Maximum likelihood estimation for the gamma distribution using data containing zeros. Journal of Climate 3, 1495-1501.

WWAP (2012). The United Nations World Water Development Report 4: Managing Water under Uncertainty and Risk. Paris: World Water Assessment Programme, UNESCO. 


\section{Figures and Tables}

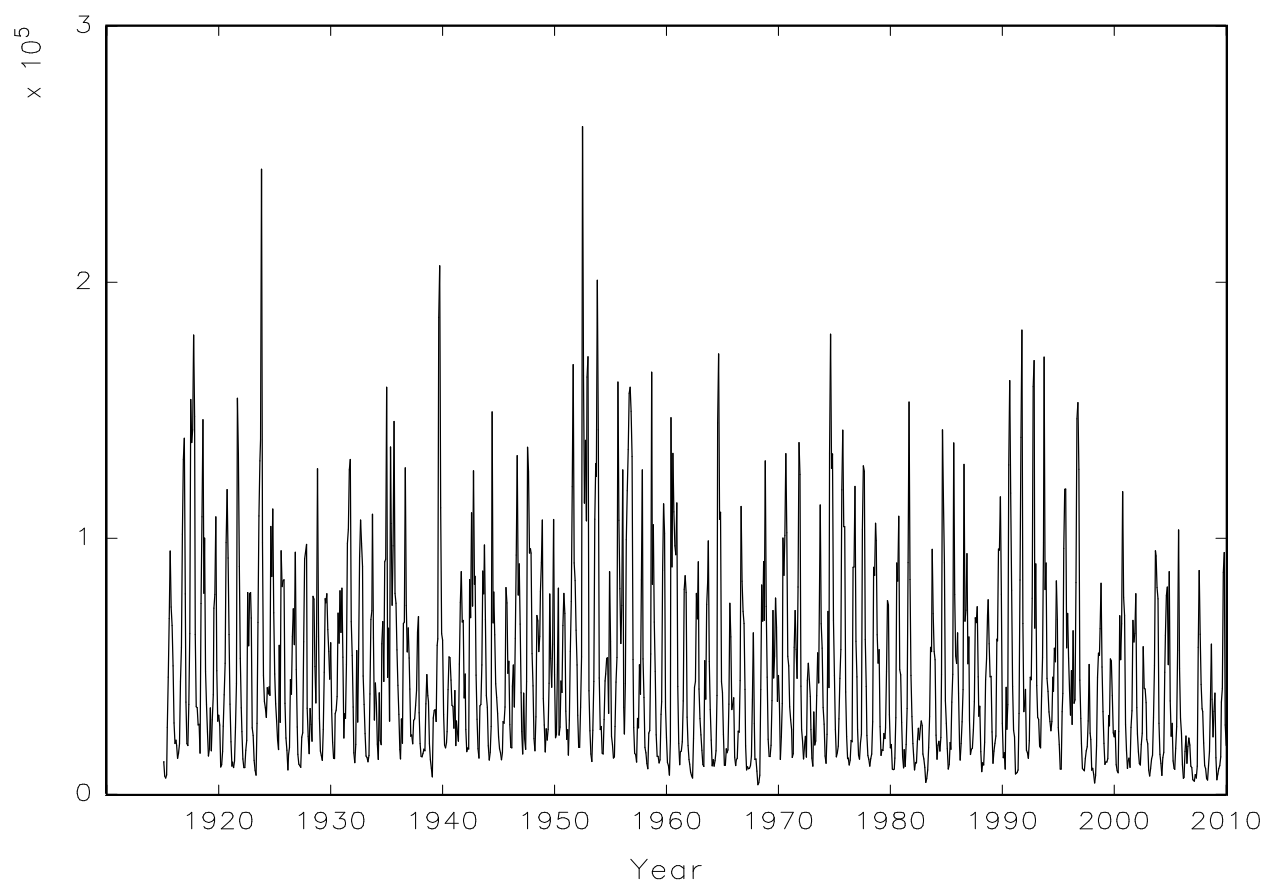

Figure 1: Reservoir inflows per month, in $M L$, total of 4 sites, January 1915 to December 2010. 


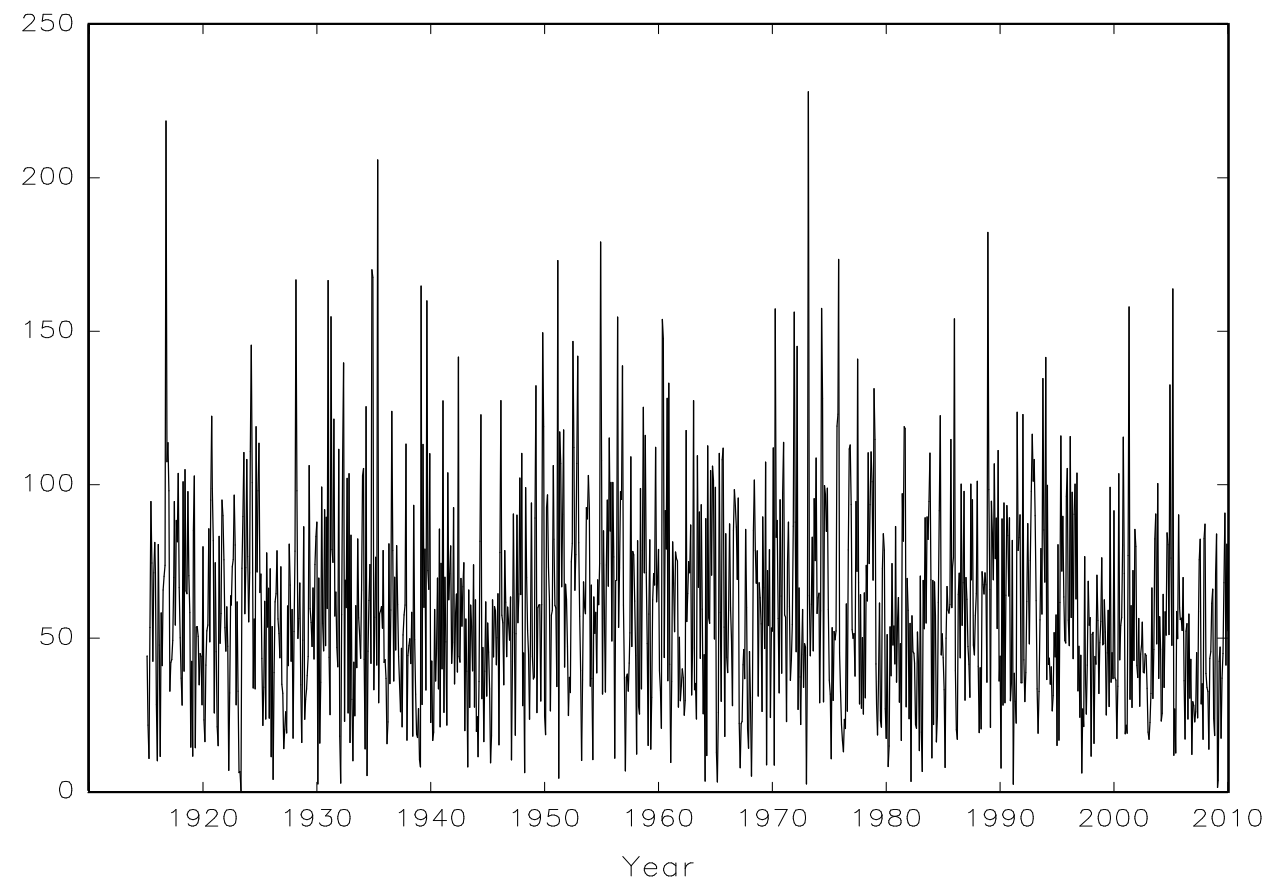

Figure 2: Rainfall per month, in $m m$, average of 6 sites, January 1915 to December 2010. 


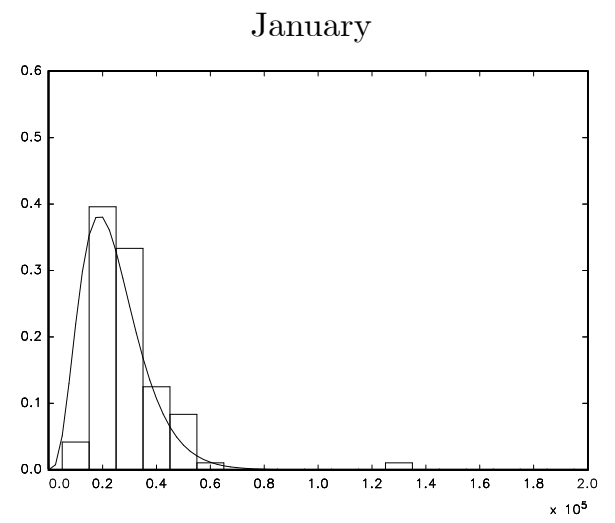

July

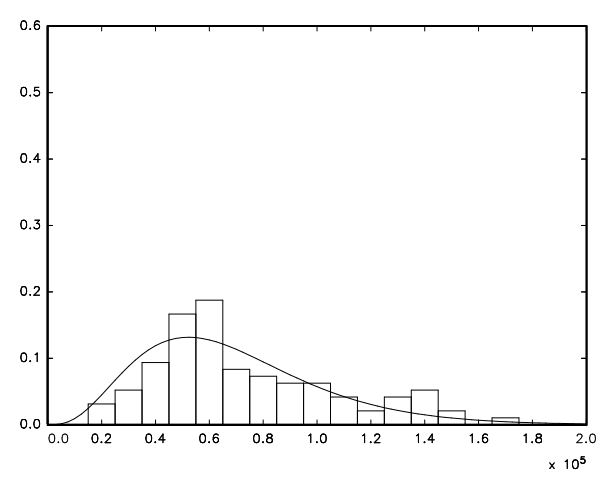

April

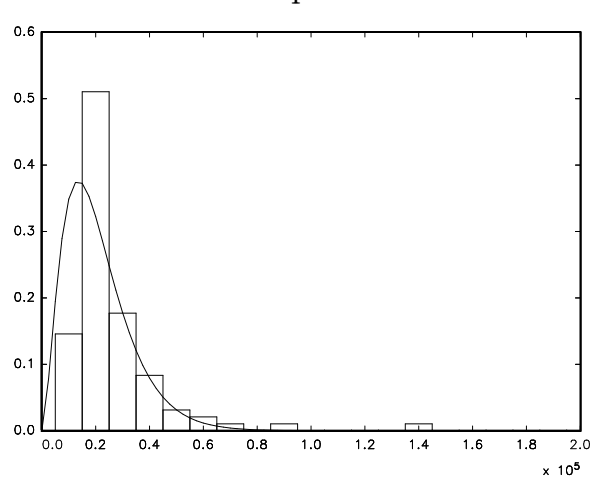

October

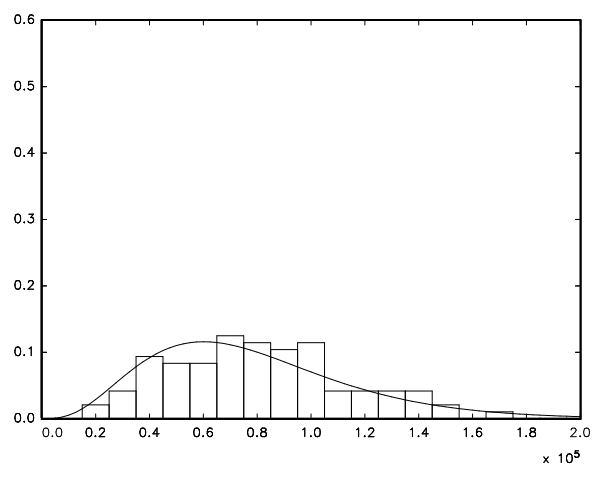

Figure 3: Empirical and estimated distributions of reservoir inflows (in $M L$ per month) for selected months, where the estimated distributions are based on the parameter estimates in table 2 . 
January

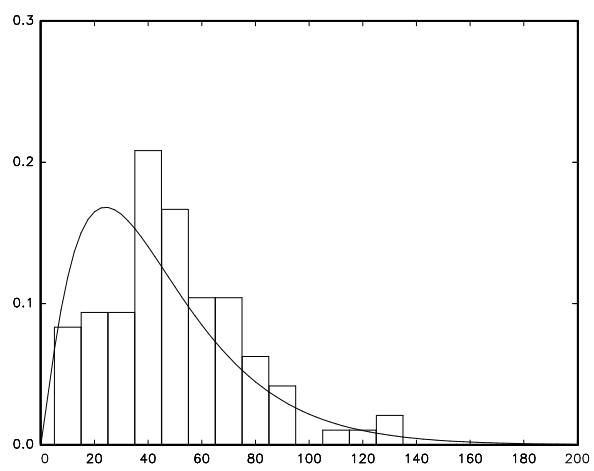

July

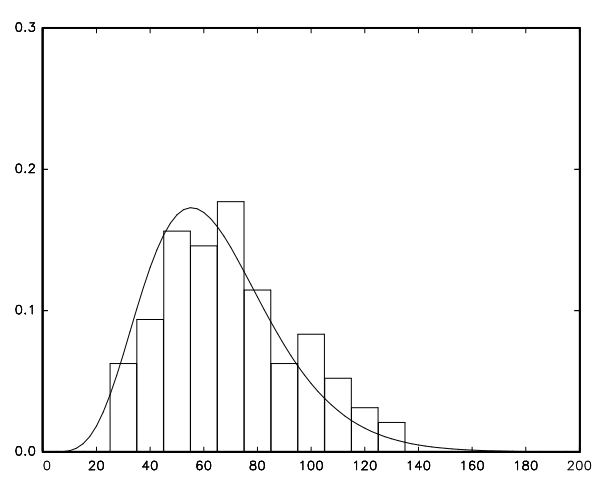

April

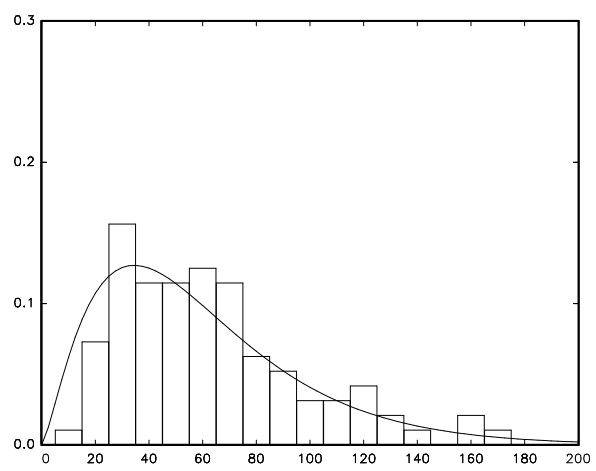

October

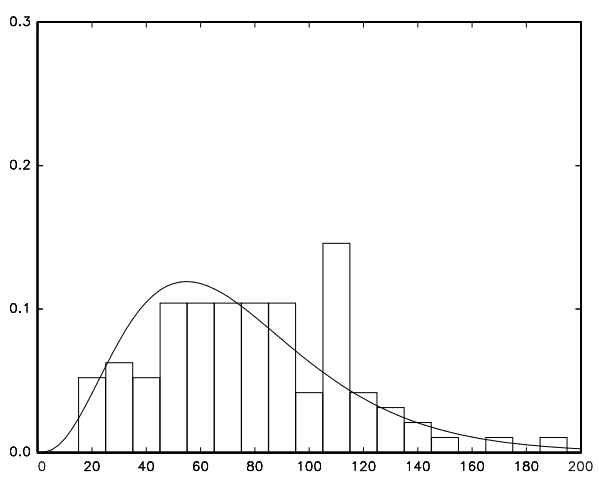

Figure 4: Empirical and estimated distributions of rainfall (in $\mathrm{mm}$ per month) for selected months, where the estimated distributions are based on the parameter estimates in table 2 . 
a) Reservoirs

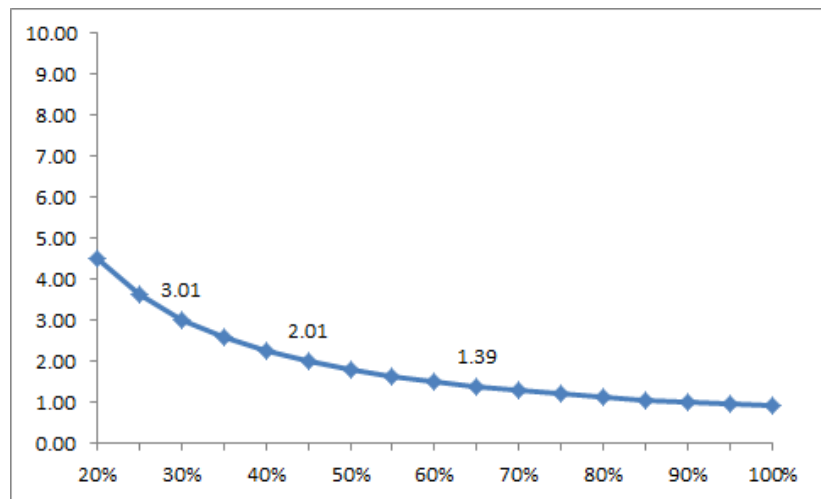

b) Stormwater harvesting

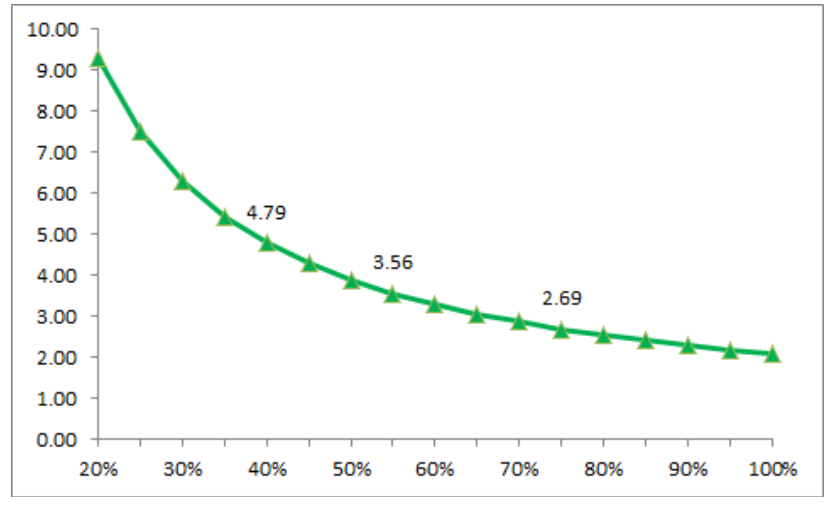

Figure 5: Total unit supply costs $(\$ / \mathrm{kL})$ by asset in terms of capacity utilization (\%).

Costs are based on (3), using the cost parameters reported in table 3 . 
a) System in Crisis

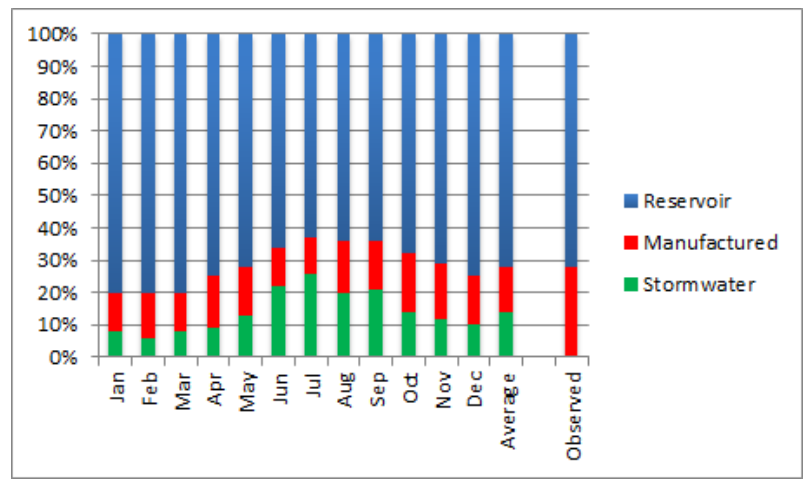

b) Average System

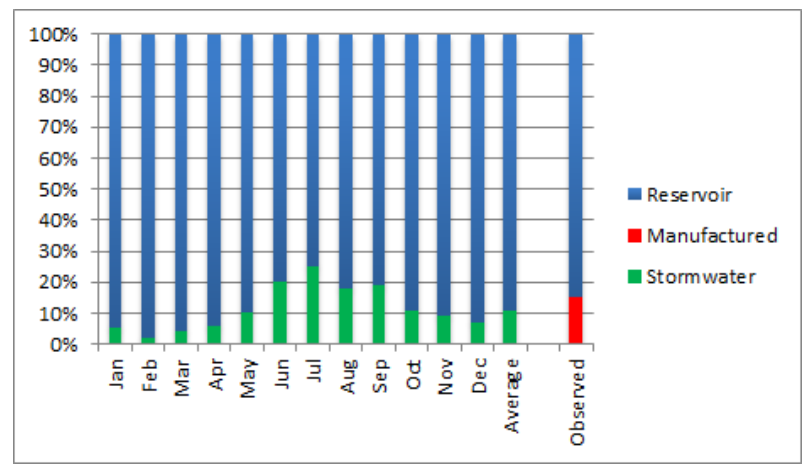

c) Vulnerable System

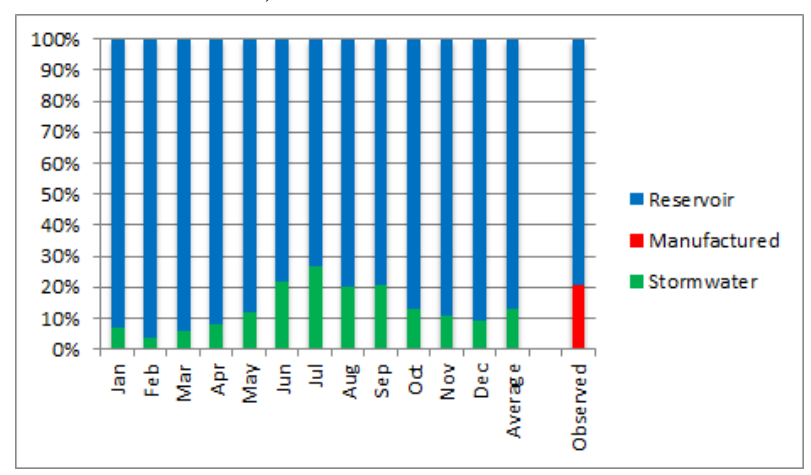

Figure 6: Optimal contributions to total water stock per month and per annum when reserve sizes for reservoir and stormwater are: a) 30\% and $40 \%$ for a system in crisis, b) $65 \%$ and $85 \%$ for an average system and c) $45 \%$ and $75 \%$ for a vulnerable system.

i) Reported shares are based on (24), (25) and (8).

ii) A non- negativity restriction is imposed on some shares that are reported as being zero.

iii) Averages are based on optimal monthly averages.

iv) Observed shares are the actual contributions to Melbourne's total water stock when reserve sizes are critical, average and vulnerable. 
Table 1:

Descriptive statistics of reservoir inflows (in $M L$ per month) and rainfall (in $m m$ per month), January 1915 to December 2010. Reservoir inflows are based on total inflows per month across 4 sites. Rainfall based on average precipitation per month across 6 sites.

\begin{tabular}{|c|c|c|c|c|c|c|c|c|}
\hline \multirow[t]{2}{*}{ Month } & \multicolumn{4}{|c|}{ Inflows $(M L)$} & \multicolumn{4}{|c|}{ Rainfall $(\mathrm{mm})$} \\
\hline & Mean & $\mathrm{SD}$ & Min & Max & Mean & $\mathrm{SD}$ & Min & Max \\
\hline Jan. & 24291 & 14335 & 5443 & 126692 & 44 & 26 & 1 & 127 \\
\hline Feb. & 16912 & 9194 & 3684 & 64859 & 49 & 44 & 2 & 228 \\
\hline March & 16356 & 8313 & 4472 & 50754 & 47 & 34 & 4 & 157 \\
\hline April & 21133 & 17286 & 5548 & 135676 & 60 & 38 & 0 & 206 \\
\hline May & 33270 & 26546 & 9484 & 149401 & 63 & 32 & 5 & 155 \\
\hline June & 48583 & 33924 & 11203 & 260871 & 62 & 25 & 9 & 147 \\
\hline July & 68868 & 34311 & 14902 & 163658 & 65 & 24 & 21 & 124 \\
\hline Aug. & 90244 & 40075 & 21994 & 186336 & 72 & 28 & 16 & 160 \\
\hline Sept. & 89291 & 35940 & 19267 & 206494 & 70 & 31 & 19 & 219 \\
\hline Oct. & 78766 & 38781 & 10956 & 244167 & 74 & 35 & 12 & 182 \\
\hline Nov. & 56952 & 30324 & 10411 & 162965 & 67 & 37 & 13 & 182 \\
\hline Dec. & 39392 & 24408 & 5806 & 170884 & 58 & 35 & 2 & 167 \\
\hline Total p.a. ${ }^{(a)}$ & 584058 & 195424 & 163337 & 1272555 & 729 & 147 & 425 & 1060 \\
\hline
\end{tabular}

(a) Based on annual data. 
Table 2:

Parameter estimates of the gamma distribution parameters, $\alpha$ and $\beta$ in (28), for reservoir inflows (in $M L$ per month) and rainfall (in $\mathrm{mm}$ per month), January 1915 to December 2010. Reservoir inflows are based on total inflows per month across 4 sites. Rainfall based on average precipitation per month across 6 sites.

\begin{tabular}{lrrrrr}
\hline \hline \multirow{2}{*}{ Month } & \multicolumn{2}{c}{ Inflows } & & \multicolumn{2}{c}{ Rainfall } \\
\cline { 2 - 3 } \cline { 6 - 6 } & $\alpha$ & $\beta$ & & $\alpha$ & $\beta$ \\
& & & & & \\
\hline Jan. & 4.416 & 5500.828 & & 2.185 & 20.335 \\
Feb. & 4.277 & 3954.134 & & 1.373 & 35.469 \\
March & 4.648 & 3518.987 & & 1.975 & 23.560 \\
April & 2.795 & 7561.184 & & 2.359 & 25.357 \\
May & 2.541 & 13093.56 & & 3.544 & 17.772 \\
June & 3.092 & 15712.92 & & 5.715 & 10.766 \\
July & 4.136 & 16650.89 & & 6.918 & 9.354 \\
Aug. & 4.961 & 18189.19 & & 5.640 & 12.722 \\
Sept. & 6.196 & 14412.25 & & 5.759 & 12.112 \\
Oct. & 4.205 & 18731.04 & & 3.843 & 19.281 \\
Nov. & 3.778 & 15074.82 & & 3.309 & 20.163 \\
Dec. & 3.691 & 10671.64 & & 2.536 & 22.736 \\
\hline & & & & & \\
Total p.a. ${ }^{(a)}$ & 8.878 & 65790.561 & & 23.802 & 30.615 \\
& & & & & \\
\hline
\end{tabular}

(a) Based on annual data. 
Table 3:

Parameter values for Melbourne.

\begin{tabular}{lrll}
\hline \hline & & & \\
Parameter & Value & Unit & \\
& & & \\
& 1290 & $G L$ & Description \\
& 0.22 & $G L$ & Tarval reservoir capacity \\
& 150 & $G L$ & Desalination plant capacity \\
$K_{r}$ & 1166 & $\$ m$ & Fixed reservoir capital costs p.a. \\
$K_{h}$ & 0.39 & $\$ m$ & Fixed stormwater capital costs p.a. \\
$K_{m}$ & 656 & $\$ m$ & Fixed desalination capital costs p.a. \\
& 0.00 & $\$ / k L$ & Reservoir operating costs per unit \\
& 0.29 & $\$ / k L$ & Stormwater operating costs per unit \\
& 1.08 & $\$ / k L$ & Desalination operating costs per unit \\
& 355 & $h a$ & Average stormwater catchment area per site \\
& 0.10 & & Stormwater harvesting rate \\
$\mu_{r}$ & 584 & $G L$ & Mean reservoir inflow \\
$\mu_{h}$ & 0.26 & $G L$ & Mean harvested stormwater \\
$\mu_{m}$ & 0 & $G L$ & Mean flow from desalination \\
$\sigma_{r}$ & 197 & $G L$ & Standard deviation of reservoir inflows \\
$\sigma_{h}$ & 0.14 & $G L$ & Standard deviation of harvested volume \\
$\sigma_{m}$ & 0 & $M L$ & Standard deviation of desalination flow \\
$\rho$ & 0.48 & & Correlation coefficient \\
$p$ & 2.47 & $\$ / k L$ & Water price \\
$\xi$ & 0.02 & & Population growth rate \\
$\delta$ & 0.03 & & Rate of discount \\
$\gamma$ & 3.5 & & Implied constant parameter of risk aversion \\
& & & \\
\hline & & &
\end{tabular}


Table 4:

System dependent parameter values for Melbourne.

\begin{tabular}{|c|c|c|c|c|c|}
\hline \multirow[t]{2}{*}{ Parameter } & \multicolumn{3}{|c|}{ Value } & \multirow[t]{2}{*}{ Unit } & \multirow[t]{2}{*}{ Description } \\
\hline & Crisis & Average & Vulnerable & & \\
\hline$S_{r}$ & 387.00 & 839.00 & 581.00 & $G L$ & Reservoir stock $\left.{ }^{a}\right)$ \\
\hline$S_{h}$ & 0.09 & 0.18 & 0.16 & $G L$ & Harvested stormwater stock ${ }^{b)}$ \\
\hline$S_{m}$ & 150.00 & 150.00 & 150.00 & $G L$ & Stock of desalinated water \\
\hline$c_{r}$ & 3.01 & 1.39 & 2.01 & $\$ / k L$ & Total average cost of reservoir water \\
\hline$c_{h}$ & 4.79 & 2.69 & 3.56 & $\$ / k L$ & Total average cost of harvested stormwater \\
\hline$c_{m}$ & 5.45 & 5.45 & 5.45 & $\$ / k L$ & Total average cost of desalinated water \\
\hline
\end{tabular}

(a) Reservoir stocks in crisis, average and vulnerable years are based respectively on $30 \%, 65 \%$ and $45 \%$ use of total capacity.

(b) Harvested stormwater stocks in crisis, average and vulnerable years are based respectively on $40 \%$, $75 \%$ and $55 \%$ use of total capacity. 
Table 5:

Optimal and observed consumption and contributions to total water stock by asset in $G L$.

\begin{tabular}{|c|c|c|c|c|c|c|}
\hline \multirow[t]{2}{*}{ Asset } & \multicolumn{2}{|c|}{ System in Crisis } & \multicolumn{2}{|c|}{ Average System } & \multicolumn{2}{|c|}{ Vulnerable System } \\
\hline & Optimal $^{a}$ & Observed & Optimal $^{a}$ & Observed & Optimal $^{a}$ & Observed \\
\hline Reservoirs & 384 & 387 & 877 & 839 & 633 & 581 \\
\hline Harvesting & 76 & 0.09 & 112 & 0.18 & 98 & 0.16 \\
\hline Desalination & 77 & 150 & 0 & 150 & 0 & 150 \\
\hline Total & 537 & 537 & 989 & 989 & 731 & 731 \\
\hline Consumption $^{b}$ & 268 & 370 & 434 & 500 & 365 & 366 \\
\hline
\end{tabular}

(a) Optimal annual contributions are based on the average shares $\left(\theta_{i}\right)$, reported in figure 6 and the total physical water stock $\left(S=\sum S_{i}\right)$, which is reported in line 5 of this table.

(b) The observed consumption levels for crisis, average and vulnerable systems are respectively the quantities of water demanded in 2001/02 (pre-drought), 2007/08, and 2011/12 (post-drought). 
Table 6:

Optimal and observed installed capacities by asset in $G L$.

\begin{tabular}{|c|c|c|c|c|}
\hline \multirow[b]{2}{*}{ Asset } & \multicolumn{3}{|c|}{ Optimal Capacities ${ }^{a}$} & \multirow[t]{2}{*}{ Observed Capacities } \\
\hline & $\begin{array}{l}\text { System } \\
\text { in Crisis }\end{array}$ & $\begin{array}{l}\text { Average } \\
\text { System }\end{array}$ & $\begin{array}{c}\text { Vulnerable } \\
\text { System }\end{array}$ & \\
\hline Reservoirs & 1280 & 1349 & 1407 & 1290 \\
\hline Harvesting & 190 & 149 & 178 & 0.22 \\
\hline Desalination & 77 & 0 & 0 & 150 \\
\hline Total & 1447 & 1498 & 1585 & 1440 \\
\hline
\end{tabular}

(a) Optimal capacities are based on the optimal contributions reported in table 5 and the system specific capacity utilizations described in footnotes a) and b) of table 4 . 
Table 7:

Total supply costs of observed and optimal water portfolios in $\$ m$.

\begin{tabular}{lrrr}
\hline \hline Total Portfolio Cost & \\
& $\begin{array}{l}\text { System } \\
\text { in Crisis }\end{array}$ & $\begin{array}{c}\text { Average } \\
\text { System }\end{array}$ & $\begin{array}{c}\text { Vulnerable } \\
\text { System }\end{array}$ \\
\hline $\begin{array}{l}\text { Observed } \\
\text { Optimal }\end{array}$ & 1984 & 1984 & 1984 \\
& 1941 & 1520 & 1619 \\
Net Savings & 43 & 463 & 365 \\
\hline
\end{tabular}

(a) Total portfolio costs are based on $\sum c_{i} \theta_{i} S$, where $c_{i}$ are the unit costs reported in table $4, \theta_{i}$ are the average shares reported in figure 6 and total physical water stock $\left(S=\sum S_{i}\right)$, reported in table 5 , line 5 , columns $3-5$.

(b) The observed reservoir contribution is calculated as $S-150000 M L-217 M L$. 


\section{Notes}

${ }^{1}$ To account for increasing capital costs along the capital expansion path, it is straightforward to specify capital costs as a function of the number of assets, $K_{i}\left(N_{i}\right)$. This specification would result in additional terms on the left-hand side of equation (5).

${ }^{2}$ This specification of operating costs may also contain risk premia for uncertainty in operating costs, for example due to uncertain future energy prices and their effects on the costs of desalination.

${ }^{3}$ A map of HQCS Network in Victoria is available from the Australian Government Bureau of Meteorology at http://www.bom.gov.au/climate/change/hqsites/; accessed 12/12/11).

${ }^{4}$ This implies an active storage of $620 k L$ per ha of urban stormwater catchment, which is ample to satisfy a seasonal demand of $\mu_{h}=0.26 G L$ (or $730 k L / h a$ ) with a long term volumetric reliability of $75 \%$ (Mitchell et al., 2006).

${ }^{5}$ The annualized capital costs for reservoir, harvested stormwater systems and desalination are inferred respectively from MW (2013); CWSC (2011); PC (2011). Average per unit capital costs are calculated as a proportion of total unit costs, which are then scaled by the long run capital utilization in each system.

${ }^{6}$ The values for the risk aversion parameter range from $3.1<\gamma<3.9$ throughout the year.

${ }^{7}$ These cost savings increase to $102 m$ per year when positive externalities of $\$ 1.02 / k L$ of stormwater harvesting (e.g. benefits from biofiltration and reduced runoff into the local waterways (CWSC, 2011)) and the negative externalities from greenhouse gas emissions associated with the desalination process of $0.18 \$ / k L$ (DTPLI, 2009) are taken into acount.

${ }^{8}$ It is unlikely that the desalination plant will run at full capacity in years of average natural supply. However, the contractual arrangements for the public-private partnership are such that even an order of zero ML from the desalination plant incurs a cost of around $\$ 610 m$ per year (MW, 2013).

${ }^{9}$ This result also holds when stocks are reduced to $40 \%$ and $50 \%$ capacity for reservoirs and stormwater harvesting respectively. 


\section{University Library}

\section{- M M I E E R VA A gateway to Melbourne's research publications}

Minerva Access is the Institutional Repository of The University of Melbourne

Author/s:

Leroux, AD;Martin, VL

Title:

Hedging Supply Risks: An Optimal Water Portfolio

Date:

2016

Citation:

Leroux, A. D. \& Martin, V. L. (2016). Hedging Supply Risks: An Optimal Water Portfolio. American Journal of Agricultural Economics, 98 (1), pp.276-296. https://doi.org/10.1093/ ajae/aav014.

Persistent Link:

http://hdl.handle.net/11343/128248 